JURNAL MEDIA INFORMATIKA BUDIDARMA

Volume 5, Nomor 3, Juli 2021, Page 922-928

ISSN 2614-5278 (media cetak), ISSN 2548-8368 (media online)

Available Online at https://ejurnal.stmik-budidarma.ac.id/index.php/mib

DOI 10.30865/mib.v5i3.3048

\title{
Penerapan Metode Technique for Orders Preference by Similarity to Ideal Solution (TOPSIS) dan Rank Order Centroid (ROC) Dalam Pemberian Beasiswa Kartu Indonesia Pintar (KIP)
}

\author{
Ita Arfyanti* \\ STMIK Widya Cipta Dharma, Samarinda, Indonesia \\ Email: 1,*ita@wicida.ac.id \\ Email Penulis Korespondensi: ita@wicida.ac.id
}

\begin{abstract}
Abstrak-Pemberian beasiswa KIP yang merupakan beasiswa bantuan yang diberikan ketika seseorang masih duduk di bangku pendidikan SMA/SMK atau batuan bagi lulusan SMA/SMK untuk melanjutkan pendidikan perkuliahan. Bantuan ini diberikan kepada siswa yang memiliki potensi akademik yang baik dan memiliki keterbatasan ekonomi. Pada saat mencari dan menentukan penerikma bantuan beasiswa terhadap penerima beasiswa KIP dengan menerapkan sistem pendukung keputusan menggunakan pendekatan metode Technique for Orders Preference by Similarity to Ideal Solution (TOPSIS) dimana kriteria pemilihan sudah ditentukan sebelumnya, kriteria tersebut dilakukan pemberian atau penilaian bobot menggunakan metode ROC (Rank Order Centroid), agar pada proses data pemilihan akan mendapatkan hasil yang lebih optimal dalam menggunakan metode TOPSIS, hasil yang didapatkan adalah sebesar 0,66061 yag merupakan nilai tertinggi dari keseluruhan data alternatif dan dalam penelitian ini memperlihatkan data lebih membentuk kepada pemilihan alternative yang berpotensi mendapatkan beasiswa KIP dengan bobot dan proses ranking yang lebih akurat.
\end{abstract}

Kata Kunci: TOPSIS; ROC; Beasiswa KIP.

\begin{abstract}
The provision of KIP scholarships, which are aid scholarships given when a person is still in high school/vocational school, or assistance for high school/vocational high school graduates to continue their education. This assistance is given to students who have good academic potential and have economic limitations. When searching for and determining recipients of scholarship assistance for KIP scholarship recipients by implementing a decision support system using the Technique for Orders Preference by Similarity to Ideal Solution (TOPSIS) method approach where the selection criteria have been determined previously, the criteria are given or weighted using the ROC method ( Rank Order Centroid), so that the election data process will get more optimal results using the TOPSIS method, the results obtained are 0.66061 which is the highest value of all alternative data and in this study shows the data is more shaped to the selection of potential alternatives. get a KIP scholarship with a more accurate weight and ranking process.
\end{abstract}

Keywords: TOPSIS; ROC; KIP Scholarship

\section{PENDAHULUAN}

Pendidikan merupakan kebutuhan utama masyarakat dan pemerintah untuk terus melangkah dalam menjawab tantangan dunia yang semakin lama semakin membutuhkan ilmu terhadap pengetahuan dan pembaharuan dari setiap pembelajaran agar menyeimbangkan negara dengan perkembangan dunia diluar sana, pendidikan juga sebagai motor dan cerminan bangsa dan pendidikan juga yang menentukan baik tidaknya kehidupan bangsa maupun individual kedepannya. Pendidikan sudah menjadi lading bisnis bagi para pebisnis dunia dikarenakan setiap orang tentunya menginginkan anak maupun diri sendiri memiliki pendidikan setinggi-tingginya, tetapi untuk mendapatkan pendidikan tentunya dibutuhkan biaya yang cukup besar dan waktu yang cukup lama[1]. Hal yang paling mendasar membuat banyak masyarakat Indonesia tidak mengenyam pendidikan dikarenakan faktor ketidak mampu dalam memenuhi biaya pendidikan khususnya melanjutkan pendidikan ke perguruan tinggi, hal tersebut juga menjadi perhatian khusus pemerintah dalam membantu mewujudkan impian anak bangsa untuk mampu mengatasi biaya pendidikan dan meraih cita-cita anak bangsa yang nantinya akan menjadi ujung tombak kemajuan negara sehingga kepala negara Indonesia atau Presiden memutuskan untuk membuat bantuan beasiswa[2].

Beasiswa merupakan kegiatan amal dari pihak swasta maupun pemerintahan untuk mewujudkan cita-cita anak-anak bangsa yang ingin terus menimba ilmu pengetahuan yang lebih, beasiswa juga akan mempermudah seseorang penerimanya untuk mendapatkan fasilitas yang cukup dalam melanjutkan studinya, jenis dari sumber pemberi beasiswa beraneka ragam, baik secara individual/pribadi, kelompok organisasi seperti perusahaan swasta, gerakan peduli masyarakat banyak terhadap pendidikan maupun bersumber dari pemerintahan. Sumber beasiswa dari pemerintahaan beraneka ragam salah satunya dalam bentuk Kartu Indonesia Pintar (KIP) atau singkatan dari kartu Indonesia pintar, yang merupakan program dari presiden republik Indonesia. Dengan adanya KIP sangat membantu dan memberikan identitas baru kepada siswa lulusan SMA/SMK yang ingin melanjutkan perkuliahannya sesuai dengan jurusan yang diharapkan pesarta penerima bantuan KIP[3].

KIP diberikan kepada siswa yang tampak memiliki potensi baik terhadap nilai-nilai akademik, siswa dan juga kepada siswa yang kurang mampu untuk biaya perkuliahan, peserta KIP tentulah sangat banyak dan berasal dari banyak data pula, kerap sekali data yang ditampung membuat proses seleksi penerimaan beasiswa KIP terhalang dan memakan waktu yang cukup lama, sering juga dalam proses penentuan tingkat penting dari sebuah persyaratan yang sudah ditentukan oleh pihak penyelenggara KIP belum optimal sehingga perlu dilakukan bantuan sebuah sistem komputer yang membantu dalam pengolahan dan penentuan pemberian beasiswa KIP. Pada penelitian ini sebuah sistem komputer akan diterapkan sebuah metode ROC (Rank Order Centroid) dan 
JURNAL MEDIA INFORMATIKA BUDIDARMA

Volume 5, Nomor 3, Juli 2021, Page 922-928

ISSN 2614-5278 (media cetak), ISSN 2548-8368 (media online)

Available Online at https://ejurnal.stmik-budidarma.ac.id/index.php/mib

DOI 10.30865/mib.v5i3.3048

dikombinasikan dengan metode Technique for Orders Preference by Similarity to Ideal Solution (TOPSIS) [4] untuk menerangkan penggunaan dan pengolahan kriteria dari penentuan penerimaan beasiswa KIP tersebut, kriteria yang telah ditentukan nantinya akan diberikan nilai berupa nilai bobot yang nantinya akan menjadi dari tingkat kepentingan sebuah kriteria, selanjutnya dilakukan seleksi terhadap alternatif dalam menentukan nilai dari kriteria keseluruhan terhadap alternatif menggunakan TOPSIS[5].

Pada penelitian terdahulu metode ROC (Rank Order Centroid) membantu proses dalam pencarian nilai bobot terhadap uji sensitive terhadap variabel dan kriteria untuk melakukan optimalisasi untuk menghindari alarm terhadap sistem secara besar-besar dan mendapatkan hasil optimalisasi dan pengurangan alarm yang signifikan dan akurat[6], penelitian terhadap ROC juga digunakan untuk melengkapi penelitian dalam pengambilan keputusan yang berfungsi sebagai penentu nilai batas terhadap persentase bobot dari kriteria pengujian untuk menentukan pemberian bantuan beasiswa kepada siswa miskin dengan hasil yang baik dan pengerjaan yang sangat sederhana menggunakan meted SAW dalam penentuan rank terhadap bobot yang telah diukur [7].

Pada penelitian terdahulu lainnya menggunakan metode TOPSIS untuk mengetahui baiknya sebuah tingkatan procedural yang diuji menggunakan metode ini dan memperlihatkan koherasi terhadap peringkat yang sudah ditemukan[8]. Penelitian lainnya memperlihatkan kemampuan TOPSIS dalam menentukan pemilihan jasa ekspedisi yang tepat sebagai rekomendasi yang dapat dipilihkan oleh customer sebagai alternatife terbaik dan sesuai dengan keinginan customers[4][9].

Dari penjelasan di atas, penulis menggunakan metode TOPSIS dan ROC untuk melakukan seleksi dalam pemberian beasiswa Kartu Indonesia Pintar (KIP). Hasil dari penelitian diharapkan pimpinan akan lebih objektif dalam menghasilkan keputusan terhadap penerima beasiswa KIP tersebut.

\section{METODOLOGI PENELITIAN}

Metodologi penelitian ini dilakukan untuk mempermudah dalam menyelesaikan proses penyelesaian permasalahan dengan cara tepat dan bertahap, metodologi juga dikatakan sebagai konsep teoritik berbagai metode, mulai dari metode terhadap pengumpulan data, dalam menyelesaian permasalahan yang melibatkan metode penyelesaian masalah maupun algoritma, hingga teoritik dari berbagai sumber yang terkait dengan penelitian yang dijalankan. Perlu dilakukan metodologi penelitian bertujuan untuk mempermudah penulis maupun pembaca nantinya dalam memahami kegiatan yang dilakukan[10].

\subsection{Pengumpulan Data}

Pengumpulan data dilakukan dengan upaya mempermudah penelitian menemukan fakta dan penyimpangan terhadap data yang akan diteliti, pengumpulan data pada para siswa yang ingin mendapatkan beasiswa KIP sebagai siswa rekomendasi sehingga dilakukan bebrapa tahapan dalam pengumpulan data sebagai berikut ini[11][12]:

1. Wawancara

Wawancara merupakan tahapan awal yang dilakukan untuk melihat siswa yang berkompetensi dalam bidang akademik dan mengetahui beberapa data yang diperlukan untuk memenuhi standar terhadap kualitas siswa yang ditanyakan.

2. Studi Dokumen

Studi dokumen merupakan kelengkapan yang diperlukan penelitian seperti nilai, keterangan kelurga data identitas diri dan lainnya untuk bukti atau pemenuhan kebutuhan penelitian.

3. Studi Pustaka

Studi pustaka berupa sumber informasi yang didapatkan dalam mencari teoristis dan data yang diperlukan untuk membantu peneliti melihat penelitian dan sumber-sumber terpecaya sebagai landasan keakuratan dalam memenuhi data dan fakta baik berupa penjelasan tentang penelitian terdahulu baik tentang metode yang digunakan dalam menyelesaika penelitian.

4. Analisa

Pada tahapan analisa dilakukan proses mengetahui melihat dan mengamati permasalahan yag terjadi dan identifikasi terhadap bagaimana proses penyelesaian permasalahan.

5. Pengujian

Pengujian pada penelitian ini menggunaka sistem matematik untuk melihat dan memperhitungkan setiap kriteria dengan menggunakan metode yang telah ditentukan pada proses analisa sebelumnya, tujuan dari pengujian adalah mengetahui hasil dari keseluruhan proses dari penelitian untuk meneruskan proses keputusan dan menarik simpulan.

6. Kesimpulan

Tahapan kesimpulan yaitu menceritakan secara garis besar hasil dari penelitian untuk mempermudah pembaca dalam melihat hasil pada tahapan dan proses penelitian.

\subsection{Beasiswa KIP}

Beasiswa KIP atau beasiswa dari program pemerintahan berupa KIP (Kartu Indonesia Pintar) untuk membantu siswa yang ingin melanjutkan pendidikannya, kartu Indonesia pintar merupakan program unggulan dari presiden Joko 
JURNAL MEDIA INFORMATIKA BUDIDARMA

Volume 5, Nomor 3, Juli 2021, Page 922-928

ISSN 2614-5278 (media cetak), ISSN 2548-8368 (media online)

Available Online at https://ejurnal.stmik-budidarma.ac.id/index.php/mib

DOI 10.30865/mib.v5i3.3048

Widodo program pemberian kartu Indonesia pintar juga merupakan program lanjutan dalam proses kebijakan terhadap wajib pendidikan dan layanan yang diberikan perintah dalam mewujudkan cita-cita anak bangsa. KIP ditargetkan sebanyak 19 juta orang yang ditujukan untuk calon mahasiswa atau pelajar yang baru tamat pendidikan SMA/SMK yang cerdas dan kurang mampu dalam segi ekonomi sebagai pengganti dana bantuan siswa miskin sebelumnya[2][13].

\subsection{ROC}

ROC (Rank Order Centroid) dicari berdasarkan tingkat kepentingan dari kriteria, jika kriteria paling penting menurut sipencari keputusan maka datfar krtietia tersebut diurutkan menjadi nilai atau kriteria pertama, karena kriteria pertama dalam metode ROC (Rank Order Centroid) merupakan yang paling penting dan memiliki tingkat kepentingan terbesar, kriteria kedua dan ketika terendah selanjutnya dan seterunya demikian, sehingga penting dilakukan pengurutan terebih dahulu terhadap kriteria paing penting dari kriteria lainya. Adapun penjelasan terhadap hal di atas adalah sebagai berikut ini[14], [15]:

$c_{r 1} \geq c_{r 2} \geq c_{r 3} \geq \cdots \geq c_{r n}$

Maka

$W 1 \geq W 2 \geq W 3 \geq \cdots \geq W n$ berikut ini:

Selanjutnya misalnya k merupakan jumlah kriteria yang digunakan sehingga dapat dibentuk dengan tahapan

$W 1=\frac{1+\frac{1}{2}+\frac{1}{3}+\cdots+\frac{1}{k}}{k} \quad($ untuk kriteria 1$)$

$W 2=\frac{0+\frac{1}{2}+\frac{1}{3}+\cdots+\frac{1}{k}}{k} \quad($ untuk kriteria 2$)$

$W 3=\frac{0+0+\frac{1}{3}+\cdots+\frac{1}{k}}{k} \quad($ untuk kriteria 3$)$

$W k=\frac{0+0+0+\cdots+\frac{1}{k}}{k}($ untuk kriteria $\mathrm{k})$

Berikut rumusan yang dapat digunakan dalam menyelesaikan pencarian bobot:

$W k=\frac{1}{k} \sum_{i=1}^{k}\left(\frac{1}{k}\right)$

\subsection{Metode Technique for Orders Preference by Similarity to Ideal Solution (TOPSIS)}

Topsis merupakan salah satu dari metode TOPSIS merupakan salah satu metode yang ada dalam decission support atau sistem pendukung keputusan, metode ini meurpakan metode yang paling banyak digemari oleh peneliti lain dalam penyelesaian masalah dikarenakan penelitian ini mempermudah dalam proses penyelesaian masalahan, hasil akhir metode ini adalah menemukan nilai terbaik/tertinggi dari alternatif, berikut ini merupakan tahapan dalam penyelesaian permasalahan menggunakan metode TOPSIS[16]-[22]:

1. Tentukan alternatif dan kriteria-kriteria yang akan diperhitungkan menggunakan metode TOPSIS

2. Mencari dan menentukan matriks keputusan ternormalisasi dengan menggunakan rumusan berikut ini:

$$
r_{i j}=\frac{x_{i j}}{\sqrt{\sum_{i=1}^{m} x_{i j}^{2}}}
$$

3. Menentukan normalisasi terbobot.

$$
y_{i j}=w_{i} r_{i j}
$$

Dengan ketentuan :

a. Jika kriteria merupakan atribut merugikan (cost) maka rumusan yang dapat digunakan sebagai berikut ini:

$$
A^{-}=\left(y_{1}^{-}, y_{2}^{-} \ldots y_{n}^{-}\right)
$$

b. Jika kriteria merupakan atribut menguntungkan (benefit) maka rumus yang dapat digunakan sebagai berikut ini:

4. Menghitung jarak nilai terbobot.

$$
A^{+}=\left(y_{1}^{+}, y_{2}^{+} \ldots y_{n}^{+}\right)
$$

a. Jika solusi ideal nilai positif

$$
D_{i}^{+}=\sqrt{\sum_{j=1}^{n}\left(y_{1}^{+}-y_{i j}\right)^{2}}
$$


JURNAL MEDIA INFORMATIKA BUDIDARMA

Volume 5, Nomor 3, Juli 2021, Page 922-928

ISSN 2614-5278 (media cetak), ISSN 2548-8368 (media online)

Available Online at https://ejurnal.stmik-budidarma.ac.id/index.php/mib

DOI 10.30865/mib.v5i3.3048

b. Jika solusi ideal nilai negatif

$$
D_{i}^{-}=\sqrt{\sum_{j=1}^{n}\left(y_{i j}-y_{1}^{-}\right)^{2}}
$$

5. Menghitung nilai preferensi

$$
v_{i}=\frac{D_{i}^{-}}{D_{i}^{-}+D_{i}^{+}}
$$

Adapun kelebihan dan kekurangan dari metode ini adalah:

1. Kelebihan

- Kelebihan metode ini adalah metode yang memiliki tahapan konsep yang sederhana

- Mudah diaplikasikan dengan jenis permasalahan pengambilan keputusan

- Komputasinya yang efisien.

2. Kekurangan

Belum memiliki penentuan bobot kriteria yang pasti, bobot masih ditentukan secara manual sehingga data yang diolah menjadi kurang optimal

\section{HASIL DAN PEMBAHASAN}

Pemberian beasiswa KIP yang sesuai dengan prosedur adalah siswa menyiapkan berkas yang dibutuhkan dan sebagai persyaratan dari pemerintahan, selanjutnya pihak sekolah mencatat data siswa calon penerima bantuan KIP dengan memililah siapa saja yang berhak berdasarkan data pendukung dan data dari sekolah itu sendiri dan kemudian dipilah kembali atau disaring dari banyak data siswa untuk diserahkan atau diusulkan kepada Dinas yang bersangkutan.

Hal tersebut membuat sekolah wajib melakukan seleksi terhadap siswa yang akan diusulkan agar tidak terjadi kesalahan dalam memberikan calon penerima beasiswa KIP yang layak, berikut ini merukapakan kriteria yang menjadi syarat untuk bahan pertimbangan sekolah.

Tabel 1. Kriteria

\begin{tabular}{cll}
\hline ID & \multicolumn{1}{c}{ Kriteria } & \multicolumn{1}{c}{ Jenis } \\
\hline C1 & Prestasi Akademik & Benefit \\
C2 & Penghasilan Orang Tua & Cost \\
C3 & Tanggungan Orang Tua & Benefit \\
C4 & Kelengkapan surat & Benefit \\
C5 & Prestasi non akademik & Benefit \\
\hline
\end{tabular}

Selanjutnya dari data kriteria akan dilakukan pemberian bobot terhadap nilai tersebut dengan menggunakan metode ROC (Rank Order Centroid) sebagai berikut ini:

Tabel 2. Kriteria terbobot

\begin{tabular}{ll}
\hline Perhitungan ROC & Bobot ROC \\
$W 1=\frac{1+\frac{1}{2}+\frac{1}{3}+\frac{1}{4}+\frac{1}{5}}{5}$ & 0,457 \\
$W 2=\frac{0+\frac{1}{2}+\frac{1}{3}+\frac{1}{4}+\frac{1}{5}}{5}$ & 0,257 \\
$W 3=\frac{0+0+\frac{1}{3}+\frac{1}{4}+\frac{1}{5}}{5}$ & 0,156 \\
$W 3=\frac{0+0+0+\frac{1}{4}+\frac{1}{5}}{5}$ & 0,090 \\
$W 3=\frac{0+0+0+0+\frac{1}{5}}{5}$ & 0,040
\end{tabular}

Tabel 3. Kriteria terbobot

\begin{tabular}{llll}
\hline ID & Kriteria & Jenis & Bobot ROC \\
\hline C1 & Prestasi Akademik & Benefit & 0,457 \\
C2 & Penghasilan Orang Tua & Cost & 0,257 \\
\hline
\end{tabular}


JURNAL MEDIA INFORMATIKA BUDIDARMA

Volume 5, Nomor 3, Juli 2021, Page 922-928

ISSN 2614-5278 (media cetak), ISSN 2548-8368 (media online)

Available Online at https://ejurnal.stmik-budidarma.ac.id/index.php/mib

DOI 10.30865/mib.v5i3.3048

\begin{tabular}{llll}
\hline ID & Kriteria & Jenis & Bobot ROC \\
\hline C3 & Tanggungan Orang Tua & Benefit & 0,156 \\
C4 & Kelengkapan surat & Benefit & 0,090 \\
C5 & Prestasi non akademik & Benefit & 0,040 \\
\hline
\end{tabular}

Tahapan selanjutnya adalah mencari nilai keputusan menggunakan metode TOPSIS sebagai berikut ini:

1. Bentuk tabel alternatif terhadap kriteria.

Tabel 4. Kecocokan Alternatif terhadap Kriteria

\begin{tabular}{llllll}
\hline & $\begin{array}{l}\text { Prestasi } \\
\text { Akademik }\end{array}$ & $\begin{array}{l}\text { Penghasilan } \\
\text { Orang Tua }\end{array}$ & $\begin{array}{l}\text { Tanggungan } \\
\text { Orang Tua }\end{array}$ & $\begin{array}{l}\text { Kelengkapan } \\
\text { surat }\end{array}$ & $\begin{array}{l}\text { Prestasi non } \\
\text { akademik }\end{array}$ \\
\hline Asri & Sangat baik & Rp 3.000.000 & 2 & Sangat baik & baik \\
Budianto & baik & Rp 2.000.000 & 3 & Sangat baik & Sangat baik \\
Rma zai & Sangat baik & Rp 4.000.000 & 4 & Sangat baik & Sangat baik \\
Usliarni & cukup & Rp 2.000.000 & 3 & baik & cukup \\
Irtaka & Buruk & Rp 3.000.000 & 2 & cukup & Sangat baik \\
Dinda & Baik & Rp 4.000.000 & 2 & Buruk & baik \\
Arman & cukup & Rp 5.000.000 & 2 & Baik & baik \\
\hline
\end{tabular}

Tabel 4. Kecocokan Alternatif terhadap Kriteria

\begin{tabular}{llllll}
\hline & C1 & C2 & C3 & C4 & C5 \\
\hline A1 & 5 & 3.000 .000 & 2 & 5 & 4 \\
$\mathrm{~A} 2$ & 4 & 2.000 .000 & 3 & 5 & 3 \\
A3 & 5 & 4.000 .000 & 4 & 5 & 4 \\
A4 & 3 & 2.000 .000 & 3 & 4 & 3 \\
A5 & 2 & 3.000 .000 & 2 & 3 & 5 \\
A6 & 4 & 4.000 .000 & 2 & 2 & 4 \\
A7 & 3 & 5.000 .000 & 2 & 4 & 4 \\
\hline
\end{tabular}

Data diatas sebelumnya merupakan data pernyataan, sebelum melakukan tahapan perhitungan menggunakan metode TOPSIS data tersebut harus dikelolah menjadi data numerik/angka agar mudah dilakukan perhitungan selanjutnya.

2. Normalisasi

Pada tahapan normalisasi nilai keseluruhan masing-masing kriteria dijumlahkan dengan nilai yang sudah dipangkat dua lalu hasil diakarkan, hasil nilai yang telah diakarkan tersebut akan dibagikan dengan nilai masing-masing kriteria terhadap alternatif, sehingga menghasilkan nilai sebagai berikut ini:

Tabel 4. Nilai Ternormalisasi

\begin{tabular}{ccccc}
\hline 0,49029 & 0,329293 & 0,282843 & 0,456807 & 0,386695 \\
0,392232 & 0,219529 & 0,424264 & 0,456807 & 0,290021 \\
0,49029 & 0,439057 & 0,565685 & 0,456807 & 0,386695 \\
0,294174 & 0,219529 & 0,424264 & 0,365446 & 0,290021 \\
0,196116 & 0,329293 & 0,282843 & 0,274084 & 0,483368 \\
0,392232 & 0,439057 & 0,282843 & 0,182723 & 0,386695 \\
0,294174 & 0,548821 & 0,282843 & 0,365446 & 0,386695 \\
\hline
\end{tabular}

3. Nilai Normalisasi Terbobot

Pada tahapan ini hasil nilai bobot dari ROC dikalikan dengan nilai ternormalisasi sehingga hasil yang didapat seperti tabel 5 dibawah ini:

Tabel 5. Nilai Normalisasi Terbobot

\begin{tabular}{rrrrr}
\hline 0,224063 & 0,084628 & 0,044123 & 0,041113 & 0,015468 \\
0,17925 & 0,056419 & 0,066185 & 0,041113 & 0,011601 \\
0,224063 & 0,112838 & 0,088247 & 0,041113 & 0,015468 \\
0,134438 & 0,056419 & 0,066185 & 0,03289 & 0,011601 \\
0,089625 & 0,084628 & 0,044123 & 0,024668 & 0,019335 \\
0,17925 & 0,112838 & 0,044123 & 0,016445 & 0,015468 \\
0,134438 & 0,141047 & 0,044123 & 0,03289 & 0,015468 \\
\hline
\end{tabular}


JURNAL MEDIA INFORMATIKA BUDIDARMA

Volume 5, Nomor 3, Juli 2021, Page 922-928

ISSN 2614-5278 (media cetak), ISSN 2548-8368 (media online)

Available Online at https://ejurnal.stmik-budidarma.ac.id/index.php/mib

DOI 10.30865/mib.v5i3.3048

4. Mencari nilai solusi ideal positif dan negatif

Pada tahapan ini nilai ideal positif merupakan nilai maksimal dari keseluruhan masing-masing kriteria dan ideal negatif merupakan nilai terendah sehingga nilai yang didapat sebagai berikut ini:

Tabel 6. Nilai Solusi Ideal

\begin{tabular}{ccc}
\hline ID & Ideal Positif & Ideal Nrgatif \\
\hline C1 & 0,224063 & 0,089625 \\
C2 & 0,141047 & 0,056419 \\
C3 & 0,088247 & 0,044123 \\
C4 & 0,041113 & 0,016445 \\
C5 & 0,019335 & 0,011601 \\
\hline
\end{tabular}

5. Menghitung nilai jarak alternatif solusi ideal

Pada tahapan ini nilai solusi ideal dikurangi dengan nilai normalisasi terbobot sehingga hasil sebagai berikut ini:

Tabel 7. Nilai Jarak solusi Ideal

\begin{tabular}{ccc}
\hline ID & Positif & Negatif \\
\hline D1 & 0,071728086 & 0,139616227 \\
D2 & 0,098573128 & 0,095540026 \\
D3 & 0,00081106 & 0,154359693 \\
D4 & 0,125733038 & 0,052586604 \\
D5 & 0,153212183 & 0,030383922 \\
D6 & 0,048178986 & 0,105974905 \\
D7 & 0,100310371 & 0,097239253 \\
\hline
\end{tabular}

6. Mencari Nilai Preferensi

Pada tahapan ini nilai ideal negatif dibagi dengan jumlah nilai ideal positif dan negatif sehingga hasil pada tabel berikut ini:

Tabel 8. Nilai Preferensi \& Rank

\begin{tabular}{ccc}
\hline ID & Nilai & Ranking \\
\hline A1 & 0,66061 & 3 \\
A2 & 0,492187 & 5 \\
A3 & 0,994773 & 1 \\
A4 & 0,294901 & 6 \\
A5 & 0,165493 & 7 \\
A6 & 0,687462 & 2 \\
A7 & 0,492227 & 4 \\
\hline
\end{tabular}

Nilai alternatif ke 3 atau A3 merupakan kandidat atau penerima beasiswa KIP terbaik dan nilai tertinggi kedua, ketiga dan seterusnya.

\section{KESIMPULAN}

Hasil dari pencarian data dari penerima bantuan beasiswa KIP lebih mudah diproses sehingga membuat data yang lebih tepat dan objektif. Metode ROC merupakan salah satu metode pembobotan yang paling sederhana dalam proses pengerjaanya dan sangat mudah dipahami, Penggunaan metode ROC membantu menutupi kekurangan dan kelemahan dari metode TOPSIS sehingga hasil dari pengambilan keputusan menjadi lebih akurat dan optimal. Dan Data yang tertera pada hasil dan pembahasan merupakan data yang berhak diajukan, ditetapkan dan dicalonkan sebagai siswa yang layak menjadi penerima beasiswa KIP.

\section{REFERENCES}

[1] Assrani dkk., "Penentuan Penerima Bantuan Siswa Miskin Menerapkan Metode Multi Objective Optimization on The Basis of Ratio Analysis (MOORA)," JURIKOM (Jurnal Ris. Komputer), vol. 5, no. 2407-389X (Media Cetak), pp. 1-5, 2018.

[2] K. P. dan Kebudayaan, "Program Indonesia Pintar," 2018. .

[3] R. Taufiq and H. P. Sari, "Rancang Bangun Sistem Pendukung Keputusan Penentuan Jenis Beasiswa Menggunakan Knn," J. Tek. Univ. Muhammadiyah Tangerang, vol. 8, no. 1, pp. 6-10, 2019. 
JURNAL MEDIA INFORMATIKA BUDIDARMA

Volume 5, Nomor 3, Juli 2021, Page 922-928

ISSN 2614-5278 (media cetak), ISSN 2548-8368 (media online)

Available Online at https://ejurnal.stmik-budidarma.ac.id/index.php/mib

DOI 10.30865/mib.v5i3.3048

[4] I. Mutmainah and Y. Yunita, "Penerapan Metode Topsis Dalam Pemilihan Jasa Ekspedisi," J. Sisfokom (Sistem Inf. dan Komputer), vol. 10, no. 1, pp. 86-92, 2021.

[5] Jamila and S. Hartati, "Sistem Pendukung Keputusan Pemilihan Subkontrak Menggunakan Metode Entropy dan TOPSIS," IJCCS (Indonesian J. Comput. Cybern. Syst., vol. 5, no. 2, pp. 12-19, 2011.

[6] G. Zhang, Z. Wang, and H. Mei, "Sensitivity clustering and ROC curve based alarm threshold optimization," Process Saf. Environ. Prot., vol. 141, pp. 83-94, 2020.

[7] A. Yunaldi, "Sistem Pendukung Keputusan Seleksi Bantuan Siswa Miskin Menerapkan Kombinasi Metode SAW dan ROC," J. Media Inform. Budidarma, vol. 3, no. 4, p. 376, 2019.

[8] D. F. de Lima Silva and A. T. de Almeida Filho, "Sorting with TOPSIS through boundary and characteristic profiles," Comput. Ind. Eng., vol. 141, no. June 2019, p. 106328, 2020.

[9] R. K. Hondro, "MABAC: Pemilihan Penerima Bantuan Rastra Menggunakan Metode MultiAttributive Border Approximation Area Comparison," J. Mahajana Inf., vol. 3, no. 1, pp. 41-52, 2018.

[10] Albi Anggito and Johan Setiawan, Metodologi Penelitian Kuantitatif. Jawa Barat: CV Jejak, 2018.

[11] H. Hasanah, "TEKNIK-TEKNIK OBSERVASI (Sebuah Alternatif Metode Pengumpulan Data Kualitatif Ilmu-ilmu Sosial)," At-Taqaddum, vol. 8, no. 1, p. 21, 2017.

[12] A. Nursikuwagus and T. Hartono, "Implementasi Algoritma Apriori Untuk Analisis Penjualan Dengan Berbasis Web," Simetris J. Tek. Mesin, Elektro dan Ilmu Komput., vol. 7, no. 2, p. 701, 2016.

[13] E. Sugiyarti and A. Maseleno, "Sistem Pendukung Keputusan (Dss) Penyeleksian Pemilihan Penerima Beasiswa Sma N 1 Ulubelu Tanggamus Mengunakan Data Mining," Konf. Mhs. Sist. Inf., vol. 6, no. 1, pp. 62-69, 2018.

[14] A. Sucipto, "Pada Koperasi Simpan Pinjam Dengan Menggunakan," J. DISPROTEK, vol. 6, no. 1, pp. 75-87, 2015.

[15] M. Mesran, T. M. Diansyah, and F. Fadlina, "Implemententasi Metode Rank Order Centroid (ROC) dan Operational Competitiveness Rating Analysis (OCRA) dalam Penilaian Kinerja Dosen Komputer Menerapkan (Studi Kasus: STMIK Budi Darma)," Pros. Semin. Nas. Ris. Inf. Sci., vol. 1, no. September, p. 822, 2019.

[16] G. S. Mahendra, "Metode Ahp-Topsis Pada Sistem Pendukung Keputusan Penentuan Penempatan Atm," JST (Jurnal Sains dan Teknol., vol. 9, no. 2, 2020.

[17] A. P. Windarto, "Implementasi Metode Topsis Dan Saw Dalam Memberikan Reward Pelanggan," Klik - Kumpul. J. Ilmu Komput., vol. 4, no. 1, p. 88, 2017.

[18] T. Limbong et al., Sistem Pendukung Keputusan: Metode \& Implementasi. Medan: Yayasan Kita Menulis, 2020.

[19] Mesran, E. P. Sumantri, Supriyanto, S. H. Sahir, and N. K. Daulay, "Implementation of Technique for Order Preference by Similarity to Ideal Solution (TOPSIS) in Recommendations for New Position in Companies," Int. J. Inf. Syst. Technol., vol. 4, no. 2, pp. 661-669, 2021.

[20] G. Ginting, Fadlina, Mesran, A. P. U. Siahaan, and R. Rahim, “Technical Approach of TOPSIS in Decision Making,” Int. J. Recent Trends Eng. Res., vol. 3, no. 8, pp. 58-64, 2017.

[21] Jasri, D. Siregar, and R. Rahim, "Decision Support System Best Employee Assessments with Technique for Order of Preference by Similarity to Ideal Solution,” Int. J. Recent TRENDS Eng. Res., vol. 3, no. 3, pp. 6-17, 2017.

[22] D. M. Khairina, B. Santoso, and S. Maharani, "Penerapan Metode Technique For Others Preference By Similary To Ideal Solution (TOPSIS) Untuk Rekomendasi Pemilihan TV Layar Datar,” J. Nas. Teknol. dan Sist. Inf., vol. 2, no. 1, pp. 23-34, 2016. 